${ }^{1}$ Dr. Öğr. Üyesi, İstanbul Rumeli Üniversitesi, İstanbul, Türkiye, nil.konyalilar@rumeli.edu.tr

ORCID: 0000-0002-7310-7779

Başvuru/Submitted: 22/07/2021

Revizyon/Revised: 1/09/2021

Kabul/Accepted: 13/09/2021

Yayın/Online Published: 25/12/2021

Attf/Citation: Konyalılar, N., COVID-19 pandemi sürecinde havacılık sektöründe çalışanların örgütsel bağlllığının işten ayrilma niyetlerine etkisinin belirlenmesi, bmij (2021) 9 (4): 1335-1346, doi: https://doi.org/10.15295/bmij.v9i4.1894

\section{COVID-19 pandemi sürecinde havacılık sektöründe çalışanların örgütsel bağlılığının işten ayrılma niyetlerine etkisinin belirlenmesi}

\section{Determining the effect of organizational commitment of employees in the aviation sector on turnover intention during the COVID-19 pandemic process}

Nil Konyalılar ${ }^{1}$

Öz

$\mathrm{Bu}$ araştırmanın amacı havayolu sektöründe çalışan personellerin örgütsel bağlllıklarının işten ayrılma niyetine etkisinin pandemi süreci göz önüne alınarak incelenmesidir. Araştırma modelinde örgütsel bağlllık; duygusal, devam ve normatif bağllılı olmak üzere iç alt faktör olarak ele alınmıştır. Araştırmada kolayda örneklem yöntemiyle 566 anket formu toplanmıștır. Elde edilen veriler Smart PLS-SEM istatistik programında kovaryans bazlı yapısal eşitlik modeli yöntemiyle analize tabi tutulmuştur. Araştırma sonuçlarına göre personellerin çalıştıkları yere yönelik normatif bağlılıkları işten ayrılma niyetlerini negatif yönde etkilemektedir. Ancak personellerin duygusal ve devam bağlllıkları işten ayrılma niyetini negatif yönde etkilememektedir.

Anahtar Kelimeler: COVID-19, Havacılık, Örgütsel Bağlllık, İşten Ayrılma Niyeti

Jel Kodlar1: J53, M12

\begin{abstract}
This research examines the effect of organizational commitment of personnel working in the airline industry on their turnover intention, considering the pandemic process. Organizational commitment in the research model; affective, continuance and normative commitment were considered internal sub-factors. In the study, 566 questionnaires were collected with the convenience sampling method. The obtained data were analyzed using the Smart PLS-SEM statistical program's covariance-based structural equation modelling method. According to the research results, the normative commitment of the personnel towards the place where they work negatively affects their turnover intention. However, the emotional and continuance commitment of the personnel do not negatively affect the turnover intention.
\end{abstract}

Keywords: COVID-19, Airline, Organizational Commitment, Turnover Intention

Jel Codes: J53, M12 


\section{Extended Abstract}

\section{Determining the effect of organizational commitment of employees in the aviation sector on turnover intention during the COVID-19 pandemic process}

\section{Literature}

All countries have dealt with a large-scale health crisis over the past two years. The effects of this crisis, caused by a virus known as coronavirus and an epidemic called COVID-19, are seen in almost every field. COVID-19, which turned into a pandemic, was first identified in China's Wuhan Province in late 2019 with respiratory symptoms (fever, cough, shortness of breath) and was placed on January 13,2020 , because of research. COVID-19, which was initially only a local epidemic related to the region where it appeared, later spread to other provinces of China and then to the whole world and turned into a pandemic.

The employees' level of commitment to the organization is one of the factors that affect the attitudes and approaches of the employees about the institution they work for, and thus the performance and productivity outputs (Uygur, 2009). Organizational commitment can be defined as the employees' attitudes to continue working in the organization depending on their business relations (İmamoğlu, 2011). The intention to leave the job, which is used as an independent variable in the research, is defined as the employees' intention to leave the organization they are a member of voluntarily and the attitudes and behaviours that cause them to realize these goals consciously (Mobley, 1977). To put it more clearly, the intention to leave the job is the employee's thinking of going to the organization because he is dissatisfied with the opportunities he promises (Özcan, Vardarlier, Karabay, Konakay \& Çetin, 2012).

\section{Research subject}

Working in the aviation sector, one of the sectors where the effects of the pandemic are felt most deeply has become much more for employees. It is predicted that the employees' level of commitment both to the job they do and to the organization they are a member of will also be affected by this crisis. It can be thought that the severe limitation of the working conditions and opportunities offered to the employees during regular times during this crisis will affect the employees' organizational commitment and their intention to leave the job. Although many studies in the literature explain the relationship between these two variables, no studies examining a similar relationship in the context of two different parameters such as the pandemic process and the aviation sector have been found. Therefore, it is thought that this study will make a significant contribution to the literature, as it examines organizational commitment and intention to leave, which are critical for the business world during the pandemic process and in the aviation sector. In the next part of the study, the conceptual analysis of the variables and the formation of the theoretical ground are included in this study.

\section{Research purpose and importance}

This research examines the effect of organizational commitment of personnel working in the airline industry on their intention to leave, considering the pandemic process. Organizational commitment in the research model; affective, continuance and normative commitment were considered three sub-factors.

\section{Contribution of the article to the literature}

In this research, the effect of organizational commitment of airline employees on their intention to leave was examined. In this context, employees' organisational commitment prevents them from turnover intention.

\section{Design and method}

The research population consists of personnel working in the airline industry in Turkey. According to SGHM (2020) data, approximately 225 thousand personnel work in the airline industry in Turkey. Since it is impossible to reach the whole universe and mainly due to the difficulties of the pandemic conditions, sampling was preferred.

\section{Research type}

The quantitative research method was used in the research.

\section{Research problems}

The problem of this research is to explain the factors that cause airline employees' turnover intention.

\section{Data collection method}

In order to determine the number of samples, Krejcie \& Morgan (1970) used the table in which the sample size was calculated compared to the population size. In calculating the sample size, the number 387 is sufficient for the sample at the 0.05 significance level and for the population sizes less than 10,000 according to the 0.05 sampling error (Ural \& Kilıç, 2018). Therefore, within the scope of the purpose of the research, a total of 566 participants were reached with the convenience sampling method. Questionnaires were collected face to face between January 2021 and June 2021.

\section{Quantitative/qualitative analysis}

In the study, primary and secondary data collection methods were used together. The Smart PLS-SEM method was used in the research data analysis process. Firstly, confirmatory tetrad analysis (CTA) was used to determine the structure of the scales. When the CTA analysis was examined, the scales had a reflective structure, and in this context, analyzes were made in line with the covariance-based structural equation model.

\section{Research model}

Organizational commitment and turnover intention scales were used in the research model. The organizational commitment scale consists of three sub-factors: continuance, normative and emotional. 


\section{Research hypotheses}

H1: Emotional commitment negatively affects turnover intention.

$\mathrm{H} 2$ : Continuance commitment negatively affects turnover intention.

H3: Normative commitment negatively affects turnover intention.

\section{Findings and discussion}

Cognitive commitment levels of airline industry employees in their positions prevent them from leaving their jobs. It is seen that employees are satisfied with their jobs and find this situation suitable when they think about it logically. Since there is closure worldwide, the lack of alternative job opportunities makes the employees' organisational commitment meaningful in a normative way. The airline industry is an industry that requires more social processes. In addition, although the pandemic process is dangerous in environments where people are dense, it affects airline employees emotionally and in terms of attendance but leaving the job cannot be a reason. On the other hand, the pharmaceutical industry was taken as a sample in the relevant study.

\section{Findings as a result of analysis}

In this study, the effect of organizational commitment of airline industry employees on turnover intention was examined. The fact that the research was carried out, especially during the COVID-19 process, reveals the research's originality. According to the results of the analysis made within the scope of the research, it was found that normative commitment, one of the sub-factors of organizational commitment, had a positive and significant effect on the intention to leave. However, it was determined that the sub-factors of attendance and emotional commitment did not positively affect the turnover intention.

\section{Hypothesis test results}

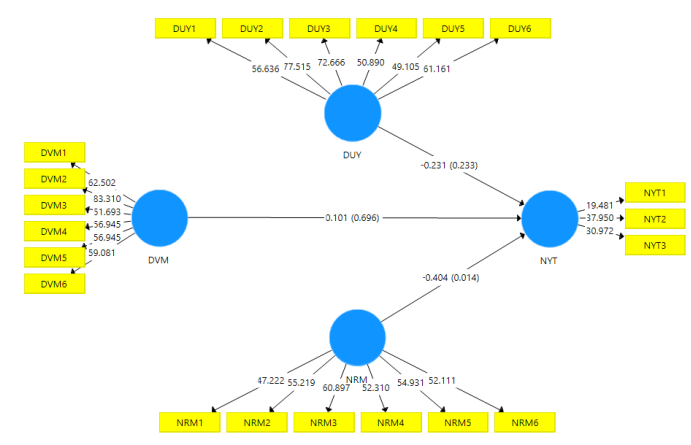

Figure 1: Research Results

\section{Discussing the findings with the literature}

It is seen that the employees are satisfied with their jobs and find this situation suitable when they think about it logically. Zincirkiran, Çelik, Ceylan \& Emhan (2015) examined whether organizational commitment affects turnover intention in their study on the energy sector. However, unlike this study, no significant adverse effect was found. The different results in the two studies may be that the authors examined organizational commitment in general. In addition, the sector difference can be shown as another reason for this situation. Finally, this research took place during the pandemic period. Since there is closure worldwide, the lack of alternative job opportunities makes the employees' organisational commitment meaningful in a normative way. In their study, Varol (2017) concluded that, unlike this research, normative commitment did not hurt the intention to leave, but emotional and continuance commitment had a positive and significant effect.

\section{Conclusion, recommendation, and limitations}

Airline employees work in an environment where the service sector is dense. In addition, the high circulation keeps the work pace high. However, systematic and coordinated business planning in the airline industry can make the business environment more positive. Therefore, the intention to leave the job may be lower in airline employees. According to the research results, it was observed that the answers given by the employees to the intention to leave the job were common.

\section{Results of the article}

In summary, the results obtained in the research show that the organizational commitment of airline employees is outstanding in the normative aspect during the pandemic process. Therefore, it can be said that this result indicates that the effect of the pandemic process is gradually decreasing in the sector.

\section{Suggestions based on results}

Airline employees were used as a sample in this study. Other sub-sectors related to the tourism sector can be investigated in future studies.

\section{Limitations of the article}

The COVID-19 pandemic process and the post-pandemic or pre-pandemic results can be evaluated in future research. Another limitation of the study is that only the employees' organisational commitment was examined in the research model. Future research can explore the effects of negative situations such as burnout, organizational justice, and mobbing on the intention to leave. 


\section{Giriş}

Tüm ülkeler son iki yıllık bir süreçte büyük ölçekli bir sağlık kriziyle mücadele etmeye çalışmaktadır. Koronavirüs olarak bilinen bir virüsün ve COVID-19 olarak isimlendirilen salgının sebep olduğu bu krizin etkileri hemen her alanda görülmektedir. Pandemiye dönüşen COVID-19, ilk olarak Çin'in Vuhan Eyaleti'nde 2019'un sonlarında görülen solunum yolu belirtileri (ateş, öksürük, nefes darlığı) olan hastalık, yapılan araştırmalar sonucunda 13 Ocak 2020'de tanımlanmıştır. Başlangıçta sadece ortaya çıktığı bölge ile ilgili lokal bir salgın olarak COViD-19 daha sonra Çin'in diğer eyaletlerine ve sonrasında da tüm dünyaya yayılarak bir pandemiye dönüşmüştür.

COVID-19'un sadece bir sağlık krizi olarak değerlendirilmesi eksik olacaktır. COViD-19 ekonomik, sosyal, eğitim ve politik yansımaları olan geniş çaplı bir krizdir (Kement, Çavuşoğlu, Demirağ, Durmaz ve Bükey, 2020). Hatta bilimsel toplantılar dahi online platformlar üzerinden yapılarak bambaşka metaforlar ile anılmaya başlamıştır (Göral, Kement ve Bükey, 2021). Pandeminin olumsuz etkilediği en önemli alanlardan biri ise beklenildiği üzere iş hayatıdır. Birçok işletme bu salgın sebebiyle çok ağır maliyetlerle karşılaşmıştır (Halis, Çamlıbel ve Bükey, 2020). Her kriz gibi COVID-19 da işletmeleri hazırlıksız yakalamış ve onları süreçlerinde radikal sayılabilecek değişiklikler yapılmasına neden olmuştur. COVID-19'un iş dünyasında en çok etkilediği sektörlerden de biri de havacılık sektördür. Çünkü virüsün yayılımının, ülkeler ve şehirlerarası geçişinin önlenmesi için alınacak tedbirlerin en başında seyahat kısıtlamaları gelmektedir. Bu durum havayolu şirketlerinin faaliyetlerini önemli ölçüde sınırlandırmıştır. Birçok araştırmacı COVID-19 pandemisinin işletmelerde yenilikçi davranış, algılanan liderlik tarzı, işten ayrılma niyeti ve örgütsel bağlllık gibi örgütsel davranış yönleriyle de olumsuz etkilerinin olduğunu göstermektedir (Hitka, Štarchoň, Caha, Lorincová ve Sedliačiková, 2021; Khanna, 2021).

Pandemi etkilerinin en derin hissedildiği sektörlerden biri olan havacılık sektöründe çalışmak, çalışanlar için çok daha zor hale gelmiştir. Çalışanların gerek yaptıkları iş ile ilgili gerek ise üyesi oldukları örgüte yönelik bağlllık düzeylerinin de bu krizde etkileneceği öngörülmektedir. Özellikle normal zamanlarda çalışanlara sunulan çalışma koşulları ve imkanlarının bu kriz esnasında oldukça sınırlandırılması çalışanların örgütsel bağlllıkları kadar işten ayrılma niyetlerinin de etkileneceği düşünülebilir. Literatürde bu iki değişken arasındaki ilişkiyi açılayan birçok çalışma olmasına rağmen benzer ilişkinin pandemi süreci ve havacılık sektörü gibi iki farklı parametreler bağlamında inceleyen çalışmalara rastlanmamıştır. Bu çalışma iş dünyası için kritik öneme sahip olan örgütsel bağlllık ve işten ayrılma niyetini pandemi sürecinde ve havacıllk sektöründe incelemesi sebebiyle literatüre anlamlı katkısının olacağı düşünülmektedir. Çalışmanın sonraki bölümünde; değişkenler kavramsal olarak incelenmesine ve teorik zemininin oluşturulmasına yer verilmiştir.

\section{Kavramsal çerçeve}

İşgörenlerin çalıştıkları kurum ile ilgili tutumlarını, yaklaşımlarını ve dolayısıyla performans ve verimlilik çıktılarını etkileyen faktörlerin başında işgörenlerin üyesi oldukları örgüte bağlılık düzeyleri gelmektedir (Uygur, 2009). Örgütsel bağlllık, iş görenlerin iş ilişkilerine bağlı olarak örgütte çalışmaya devam etme karar verme tutumları olarak tanımlanabilir (İmamoğlu, 2011). William H. Whyte'ın 1956' da yayınlanan "Örgüt İnsanı" eserine kadar dayanan ve örgütsel davranış ve psikoloji gibi konular içerisinde önemli yer tutan örgütsel bağlılık tartışmaları özünde işgörenlerin çalıştıkları örgüte karşı hissettikleri bağlllık düzeylerini konu almaktadır (Burgess ve Turner, 2000; Dick ve Metcalfe, 2001).

Örgütsel bağlılı̆̆ın çok boyutlu yapısı, açıklanmasında farklı yaklaşımların benimsenmesine neden olmuştur. Bu yaklaşımlar incelendiğinde genel olarak iki sınıfta kategorize edilebileceği görülmektedir. Yaklaşımların bir kısmı örgütsel bağlılı̆̆ı tutumsal boyutu ile ele almaktayken; bir kısmı ise davranışsal boyutu açısından örgütsel bağlllık konusunu değerlendirmiştir (Demirtaş ve Şama, 2016). Örgütsel bağll1ığı tutumsal olarak ele alan yaklaşımlardan biri olan Etzioni yaklaşımında, örgütsel bağlllık pozitif, negatif ve nötr olmak üzere üç farklı tutumla beraber ahlaki, çıkarcı ve yabancılaştııııı olmak üzere üç farklı bağlılık türü ifade edilmektedir (Newton ve Shore, 1992). Kanter (1968) yaklaşımında ise bireysel hedefler ile örgütsel amaç ve hedefleri ilişkilendirerek bu hedefler doğrultusunda çalışanların emeklerini ve performanslarını sadakatle sergilemelerini ifade etmektedir (Bakan, 2018). O'Reilly ve Chatman'ın (1986) yaklaşımı, çalışanların örgütsel değerleri içselleştirmesi ve işine sarılması devamlılı̆̆ gibi konuları kapsayan örgüt ve işgören arasındaki psikolojik bağı temel almaktadır. Bu yaklaşımda uyum, özdeşleştirme ve içselleştirme olmak üzere üç bağlllık türü söz konusudur ( $O^{\prime}$ Reilly ve Chatman, 1986). Penley ve Gould (1988) ise Etzioni'nin aksine ahlaki, çıkarcı ve yabancılaştırıcı boyutlarının tümünün bir işgörende aynı anda görülebileceğini savunmaktadır. Bu yaklaşımların tümünün ortak özelliği örgütsel bağlllığı tutumsal yönüyle ele almalarıdır. Ancak sosyal psikologlar örgütsel bağlllığ1 daha çok davranışsal boyutu ile değerlendirmiştir. Davranışsal yaklaşımların ilki Becker (1960)'in 
yaklaşımıdır. Becker'in yaklaşımının temelinde işgörenin örgüte yapmış oldukları emek, zaman, statü gibi yatırımların büyüklüğü ne kadar fazlaysa bu örgütten ayrılmasında katlanacağı maliyette o denli büyük olacağı varsayımı yer almaktadır. Bu nedenle Becker çalışanın örgüte yaptığı yatırım ne kadar fazlaysa o örgüte devamlılıkları da o kadar fazla olacağını savunmaktadır. Salancik (1977) ise Becker'in aksine örgütsel bağlılık davranışını örgütten ayrılmanın maliyetleri üzerinden değil psikolojik sebeplerle açıklamaya çalışmıştır. Örgütsel bağlılığın açıklanmasında en çok kabul gören yaklaşımlardan biri de Meyer ve Allen (1991)'in yaklaşımıdır. İlk olarak duygusal ve devam bağlılığ1 olmak üzere iki boyut yardımıyla örgütsel bağllı̆̆ı açıklamaya çalışan Meyer ve Allen daha sonra normatif bağlllığı da ekleyerek örgütsel bağl1lı̆̆ın üç boyutlu bir model ile açıklanacağını savunmuşlardır. Ancak Meyer ve Allen bu bağlllıkların birer bağllık türü olmadığını, bağlılığın birer bileşeni olduğunu ifade etmektedir (Meşe, 2007). Duygusal bağl1lık, işgörenlerin çalıştıkları örgütün üyesi olmaktan memnun olmasını sağlayan ve kendi değerleri ile örgütsel değerleri örtüşmesi sonucuyla oluşan duygu temelli bağı ifade etmektedir (Demirel, 2008). Duygusal bağlllık ile örgütte kalmaya devam edenler bir gereksinimden kaynaklı değil, istek sonucu bunu yaparlar (Balay, 2000). Devamlılık bağlılığında ise işgören örgüt için harcadığı emek ve çabayı bir yatırım olarak görmekte ve bu yatırım sonucu örgütte kalmayı bir zorunluluk olarak kabul etmektedir (Bayram, 2005). Devam bağlllığı, örgütten ayrılma durumunda katlanılacak maliyeti göze alma bu maliyeti göze alma ya da almamak ile ilgilidir. Diğer bir ifadeyle devam bağl1lı̆̆ı işgörenin örgüte yaptığı kıdem, çaba ve performans gibi yatırımlarını ve örgütten ayrılması durumunda bu yatırımları kaybetmenin maliyetlerini hesaplar eğer çok yüksek ise örgütte kalmaya devam eder (Uslu, 2012). Normatif bağlllık ise işgörenin üyesi olduğu örgüte karşı duyduğu sorumluluk inancı ile ilgilidir (Çırpan, 1999). Normatif bağımlılıkta işgörenin örgütte yer almış olduğu sürece almış olduğu uzmanlık gerektiren eğitimler, iş arkadaşlarıyla geliştirdikleri ilişkiler sebebiyle örgüte karşı borçlu hissetmeleri, işgörenlerin öğütte kalmalarının temel nedeni olarak ifade edilebilir (Ünler, 2006). Günümüzde örgütsel bağlllık ölçeklerinin çoğunun temelinde Meyer ve Allen'in Yaklaşımı yer almakta ve bu modelin ölçeği kullanılmaktadır. Bu nedenle, bu çalışmada da bu ölçek tercih edilmiştir.

Araştırmada bağımsız değişken olarak kullanılan işten ayrılma niyeti, işgörenlerin kendi istekleriyle üyesi oldukları örgütten ayrılmayı amaçlamaları ve bu amaçlarını bilinçli olarak gerçekleştirmelerine sebep olan tutum ve davranışlar olarak tanımlanmaktadır (Mobley, 1977). Daha açık ifadeyle, İşten ayrılma niyeti, işgörenin çalıştığı örgütün kendisi için vadettiği olanaklardan duyduğu memnuniyetsizlik sonucu örgütten ayrılmayı düşünmesidir (Özcan vd., 2012). Örgüt açısından oldukça olumsuz sonuçlara yol açabilecek yüksek işgücü devir hızının önüne geçebilmek için yöneticilerin yoğun bir şekilde ilgilendikleri konulardan biridir (Bertelli, 2006; Pitts, Marvel ve Fernandez, 2011). İşten ayrılma niyeti belki her zaman işten ayrılma davranışıyla sonuçlanmasa dahi bu niyete sahip kişiler yöneticiler açısından memnun edilmesi ve yönetilmesi zor işgörenler olması sebebiyle her zaman üzerinde durulması gereken konulardan biridir. İşgörenlerin işten ayrılma niyetini kendileriyle ilgili faktörler, örgütle ilgili faktörler ve çevre ile ilgili faktörler olmak üzere üç grupta sıralanabilir (Cotton ve Tuttle, 1986; Muchinsky ve Morrow, 1980). Bu çalışmada örgütsel faktörlerden biri olan örgütsel bağlllı̆̆ın işten ayrılma niyeti üzerindeki etkisi incelenecektir. Sonraki bölümde bu iki değişken arasındaki ilişkiyi ortaya koyan çalışmalara yer verilerek araştırma probleminin kuramsal zemini oluşturulmaya çalışılacaktır.

\section{Kuramsal çerçeve}

Literatürde örgütsel bağlılık ile işten ayrılma niyeti arasındaki ilişkiyi ortaya koyan sayısız çalışma bulunmaktadır (Blau ve Boal, 1987; Joo ve Park, 2010; Kement ve Batga, 2016; Tarigan ve Ariani, 2015; Bükey ve Aktaş, 2019). Tarigan ve Ariani (2015) yaptıkları çalışmada örgütsel bağlılı̆̆ın tüm boyutlarının işten ayrılma niyetini olumsuz yönde etkilediği sonucuna ulaşmışlardır. En güçlü olumsuz etkiyi yapan bileşenin ise normatif bağlılık olduğunu saptamışlardır. Ayrıca, Tarigan ve Ariani'nin ulaştığı diğer önemli bir sonuçta ise örgütsel bağlllık örgütsel hedefler için çok önemli bir faktör olan iş memnuniyetinden daha fazla işten ayrılma niyetinde belirleyici olmaktadır. Salleh, Nair ve Harun (2012) perakendecilik sektöründeki yüksek işgücü devir hızı sorunu üzerine eğildiği çalışmasında ise örgütsel bağlllı̆̆ı hem iş memnuniyeti ile işten ayrılma niyeti arasında tam aracilık ettiği hem de örgütsel bağlllık düzeyinin doğrudan işten ayrılma niyetini negatif yönde etkilediği sonucuna ulaşmıştır. Ali ve Baloch (2009) Pakistan'da uluslararası ilaç firmalarındaki çalışan 283 katılımcıyla yaptığı araştırmada örgütsel bağlılı̆̆ın işten ayrılma niyeti rol çatışması ve aile çatışması değişkenlerini içeren bir model kurmuş ve bu modele göre örgütsel bağlllı̆ı̆n işten ayrılma niyetini olumsuz yönde etkilediği sonucuna ulaşmıştır. Kanwar, Singh ve Kodwani (2012) ise bilişim sektörü ile hizmet sektörünü karşılaştırmış ve her iki sektörde de örgütsel bağlılık boyutlarının işten ayrılma niyetini olumsuz yönde etkilediği sonucuna ulaşmıştır. Üstte farklı sektörlerden toplanan bilimsel kanıtlar ışığında örgütsel bağlllık ile işten ayrılma niyeti arasında negatif yönlü ilişki olduğu görülmektedir. 
Aynı ilişkinin havacılık sektöründe ve COVID-19 pandemi sürecinde söz konusu olup olmadığını test etmek amacıyla aşağıdaki hipotezler geliştirilmiştir:

\section{$H_{1}$ : Duygusal bağhllık işten ayrlma niyetini negatif yönde etkilemektedir. \\ $\mathrm{H}_{2}$ : Devam bağhllı̆̆ işten ayrlma niyetini negatif yönde etkilemektedir. \\ $\mathbf{H}_{3}$ : Normatif bağhllık işten ayrnlma niyetini negatif yönde etkilemektedir.}

\section{Yöntem}

Araştırmanın amacı havayolu sektöründe çalışanların örgütsel bağlllıklarının işten ayrılma niyetine etkisini incelemektir. Bu bağlamda araştırma evrenini Türkiye'de havayolu sektöründe çalışan personeller oluşturmaktadır. Türkiye' de havayolu sektöründe SGHM (2020) verilerine göre yaklaşık 225 bin personel çalışmaktadır. Evrenin tamamına ulaşılması mümkün olmadığı için ve özellikle pandemi koşullarının zorlukları sebebiyle örneklem alma yoluna gidilmiştir. Örneklem sayısını belirlemek için Krejcie ve Morgan (1970) tarafından evren büyüklügüüne oranla örneklem büyüklüguünün hesaplandığı tablodan faydalanılmıştır. Örneklem büyüklügünün hesaplanmasında 0,05 anlamlılık düzeyinde ve 0,05 örneklem hatasına göre 10.000'den büyük evrenlerde 384 sayıs1 örneklem için yeterlidir (Ural ve Kılıç, 2018). Araştırmanın amacı kapsamında toplamda 566 katılımcıya kolayda örneklem yöntemiyle ulaşılmışır. Anket formları Ocak 2021 ile Haziran 2021 tarihleri arasında yüz yüze toplanmiştır.

Araştırma anket formu iki bölümden oluşmaktadır. Anket formunu birinci bölümünde katılımcıların demografik özelliklerine ilişkin veriler toplanmıştır. Araştırma kapsamında yapılan demografik bulgular incelendiğinde katılımcıların $\% 58,5^{\prime} \mathrm{i}$ erkek ve $\% 41,5^{\prime} \mathrm{i}$ kadındır. Katılımcıların yaş dağılımlarına bakıldığında, \%20,8'i 45-54, \%31,1'i 35-44, \%18,6'sı 25-34, \%8,5'i 55-64, \%8,1'i 18-24 ve $\% 6,4^{\prime} \ddot{u} 65$ yaş ve üzerindedir. Katılımcıların medeni durumlarına bakıldığında \%52,8'i bekar ve $\% 47,2^{\prime}$ si evlidir. Havayolu personelinin çalıştığı birimlere bakıldığında \%41,5'i teknik ve idari hizmetlerde, \%29,3'ü yer hizmetleri ve yine \%29,3'ü kokpit/kabin hizmetlerinde çalışmaktadır. Katılımcıların eğitim seviyelerine bakıldığında \%40'ı lisans, \%26'sı lise, \%20'si önlisans, \%7,4'ü yüksek lisans/doktora ve $\% 6,4^{\prime}$ ü ilköğretim mezunudur. Katılımcıların gelir durumlarına yönelik algıları incelendiğinde, \%38,5'i orta, $\% 29,2^{\prime}$ si yüksek, $\% 22,1^{\prime}$ i düşük, $\% 7,4^{\prime}$ ü çok düşük ve $\% 2,8^{\prime}$ i ise çok yüksek şeklinde belirtmişlerdir. Araştırmanın ikinci bölümde örgütsel bağllllğ̆ ölçmek için (Allen ve Meyer, 1990) 18 ifadeye ve işten ayrılma niyetini ölçmek için (Lance, 1988; Khatri, Fern ve Budhwar, 2001) 3 ifadeye yer verilmiştir. Anket formunda yer alan ifadeler beşli likert tipine göre katılımcılara yöneltilmiştir.

Araştırma veri analizi sürecinde Smart PLS-SEM yöntemi kullanılmıştır. Ölçeklerin yapısını belirlemek için öncelikle doğrulayıcı tetrad analizi (CTA) kullanılmıştır. CTA analizi incelendiğinde ölçeklerin reflektif yapıya sahip olduğu, bu bağlamda kovaryans bazlı yapısal eşitlik modeli doğrultusunda Consitent PLS-SEM (PLSc) ile analizler yapılmıştır.

\section{Bulgular}

\section{Ölçüm modeli sonuçları}

Araştırma modelinde yer alan ölçeklerin güvenirliği Cronbach Alpha (a) ve rho-A değerlerine bakılarak incelenmiştir. İç tutarlılığı için bütünleşik güvenirlik (CR), uyum geçerliği için ortalama açıklanan varyans (AVE), gösterge güvenilirliği için dışsal gösterge yükleri $(\lambda)$ ve ayrım geçerliliği için FornellLarcker kriteri ve HTMT (Heterotrait-Monotrait Ratio) değerleri hesaplanmıştır. Ölçeklerin gösterge yükleri, güvenirlikleri, iç tutarlılık sonuçları ve uyum iyiliği değerleri Tablo 1'de detaylı olarak gösterilmektedir.

Yapılan analizler sonucunda duygusal bağlllığın; Cronbach Alpha değeri 0,944, devam bağlllığının Cronbach Alpha değeri 0,935, normatif bağllilğın Cronbach Alpha değeri 0.934 ve işten ayrılma niyetinin Cronbach Alpha değeri 0,901 olarak hesaplanmıştır. Ayrıca rho_A değerlerine bakıldığında; duygusal bağlllığın 0,945, devam bağlllığın 0,936, normatif bağlllı̆̆ın 0,934 ve işten ayrılma niyetinin 0,911 çıkmıştır. Bu sonuçlar incelendiğinde güvenirlik katsayısı değerlerinin 0,70 üzerinde çıktı̆̆ (Hair, Risher, Sarstedt ve Ringle, 2019) ve böylelikle ölçeklerin güvenirlik değerlerinin iyi olduğu sonucuna ulaşılmıştır. Ölçeklerin bütünleşik güvenirliklerine bakıldığında; duygusal bağllık 0,944, devam bağll1ığı 0,935, normatif bağlılık 0,934 ve işten ayrılma niyeti 0,903 olarak hesaplanmış, 0,60 '1n üzerinde olduğu için (Bagozzi ve Yi, 1988) ölçeklerin iç tutarlılığı kabul edilmiştir. Ölçeklerin ortalama açıklanan varyans değerleri incelendiğinde, duygusal bağl1lık 0,739, devam bağl1lı̆̆ 0,707 , normatif bağlılık 0,703 ve işten ayrılma niyeti 0,757 olarak hesaplanmıştır. Değerler 0,50' nin üzerinde olduğu için (Fornell ve Larcker, 1981) uyum geçerliliği olduğu sonucuna ulaşılmıştır. Araştırma modelinde yer alan ölçeklere ait ifadelerin gösterge yükleri 0,50'nin üzerinde (Kaiser, 1974) çıkmıştır. Uyum iyiliği değeri olarak 
SRMR $(0,040)$ ve NFI $(0,863)$ değerleri incelenmiş ve SRMR değerinin 0,08'den düşük (Hu ve Bentler, 1999) ve NFI değerinin ise 0,80'den (Byrne, 1994) yüksek çıkmıştır. Son olarak ki-kare değerine bakılmış ve 1753,177 olarak hesaplanmıştır. Dolayısıyla araştırma modelinin iyi uyuma sahip olduğu sonucuna ulaşılmıştır.

Tablo 1: Ölçüm Modeli Sonuçları

\begin{tabular}{|c|c|c|c|c|}
\hline Değişkenler ve İfadeleri & $\lambda$ & rho_A & CR & AVE \\
\hline Duyusal Bağlılık (DUY) $(\alpha=0,944)$ & & 0,945 & 0,944 & 0,739 \\
\hline Kariyerimin geri kalanını bu işletmede geçirmekten çok mutlu olurum. & 0,834 & & & \\
\hline Gerçekten bu işletmenin sorunları bana aitmiş gibi hissediyorum. & 0,904 & & & \\
\hline Bu işletmede kendimi "ailenin bir parçası" gibi hissediyorum. & 0,889 & & & \\
\hline Bu işletmeye kendimi "duygusal olarak bağl1" hissediyorum. & 0,831 & & & \\
\hline $\mathrm{Bu}$ işletmenin benim için büyük bir kişisel anlamı var. & 0,832 & & & \\
\hline Bu organizasyona ait olduğum konusunda güçlü bir hisse sahibim. & 0,865 & & & \\
\hline Devam Bağlılı̆̆ı (DVM) $(\alpha=0,935)$ & & 0,936 & 0,935 & 0,707 \\
\hline $\begin{array}{l}\text { İstesem bile şu anda bu organizasyondaki işimden ayrılmak benim için çok zor } \\
\text { olurdu. }\end{array}$ & 0,855 & & & \\
\hline Organizasyonumdan ayrılırsam hayatımın büyük kısmı altüst olur. & 0,885 & & & \\
\hline $\begin{array}{l}\text { Benim için şu anda bu işletmede çalışmaya devam etmek, istekten daha çok bir } \\
\text { zorunluluk }\end{array}$ & 0,831 & & & \\
\hline Bu işletmeden ayrılmayı düşünmek için çok az seçeneğim olduğuna inanıyorum. & 0,813 & & & \\
\hline $\begin{array}{l}\text { Bu işletmedeki işimden ayrılmanın birkaç olumsuz sonuçlarından biri de başka } \\
\text { yerlerde mevcut alternatiflerin azlığı olacaktır. }\end{array}$ & 0,815 & & & \\
\hline $\begin{array}{l}\text { Bu işletmede çalışmaya devam etmemin en önemli nedenlerinden biri, bu işletmeden } \\
\text { ayrılmanın ciddi bir kişisel fedakârlık gerektirmesidir. }\end{array}$ & 0,844 & & & \\
\hline Normatif Bağlılık (NRM) $(\alpha=0,934)$ & & 0,934 & 0,934 & 0,703 \\
\hline Çalıştığım işletmede kalma yükümlülüğü hissediyorum & 0,838 & & & \\
\hline Avantajım olsa bile mevcut işimden ayrılmanın doğru olacağını düşünmüyorum & 0,856 & & & \\
\hline Bu işletmeden şimdi ayrılırsam kendimi suçlu hissederim. & 0,844 & & & \\
\hline $\mathrm{Bu}$ işletme sadakatimi hak ediyor & 0,831 & & & \\
\hline İşletmemden şu anda sorumluluk duygum nedeniyle ayrılmam & 0,835 & & & \\
\hline Bu işletmeye çok şey borçluyum. & 0,825 & & & \\
\hline İşten Ayrılma Niyeti (NYT) $(\alpha=0,901)$ & & 0,911 & 0,903 & 0,757 \\
\hline İşimden ayrılmayı düşünüyorum & 0,764 & & & \\
\hline $\begin{array}{l}\text { Önümüzdeki birkaç ay içinde başka bir iş bulmak için gerçek bir çaba göstermeye } \\
\text { niyetliyim. }\end{array}$ & 0,906 & & & \\
\hline İșimi sık sık bırakmayı düşünüyorum. & 0,931 & & & \\
\hline
\end{tabular}

Ölçeklerin ayrım geçerliliğini hesaplamak üzere Fornell Larcker kriteri ve HTMT sonuçlarına bakılmıştır. Fornell-Larcker sonuçları Tablo 2'de detaylı olarak verilmektedir.

Tablo 2: Fornell Larcker Kriteri Sonuçları

\begin{tabular}{lrrrr}
\hline Ölçekler & DUY & DVM & NRM & NYT \\
\hline DUY & $\mathbf{0 , 9 6 0}$ & & & \\
DVM & 0,847 & $\mathbf{0 , 9 4 1}$ & & \\
NRM & 0,887 & 0,926 & $\mathbf{0 , 9 3 8}$ & \\
NYT & $-0,493$ & $-0,492$ & $-0,515$ & $\mathbf{0 , 8 7 0}$ \\
\hline
\end{tabular}

Not: Koyu renkle gösterilen değerler Fornell Larcker Kriteri değerlerini yansıtmaktadır.

Ölçeklerin Fornell-Larcker kriterlerine bakıldığında, örgütsel bağlllık alt faktörleri ve işten ayrılma niyeti faktörü arasındaki korelasyon yüklerinden ilgili değerin yüksek olduğu (Fornell ve Larcker, 1981) tespit edilmiştir. Araştırmada ikinci ayrım geçerliliği şartı olarak HTMT sonuçlarına bakılmıştır elde edilen değerler Tablo 3'te detaylı olarak verilmektedir.

Tablo 3: Heterotrait Monotrait Ratio Sonuçları

\begin{tabular}{lcccc}
\hline Ölçekler & DUY & DVM & NRM & NYT \\
\hline DUY & & & & \\
DVM & 0,946 & & & \\
NRM & 0,886 & 0,926 & & \\
NYT & 0,495 & 0,491 & 0,515 & \\
\hline
\end{tabular}

Ölçekler arası HTMT değerleri 1,00'ın altında çıkmıştır ve bu bağlamda (Voorhees vd., 2016), ölçeklerin ayrım geçerliği olduğu tespit edilmiştir. Ölçüm modeli analizleri sonrasında yapısal model sonuçlarına geçilmiştir.

\section{Yapısal model sonuçları}

Örgütsel bağlllık alt faktörlerinin işten ayrılma niyeti üzerindeki etkisini belirlemek için R2 değerleri incelenmiştir. Örgütsel bağlılığın işten ayrılma niyetini açıklama oranı 0,27 olarak hesaplanmıştır. 
Dolayısıyla havayolu personelinin işten ayrılma niyetini örgütsel bağlılık düzeyleri \%27 etkilemektedir. Örgütsel bağlllığın işten ayrılma niyeti üzerindeki tahmini ilgi düzeyi (Q2) 0,192 olarak hesaplanmıştır. Elde edilen değer $0,15^{\prime}$ ten fazla olduğu için tahmini ilgi düzeyi yüksektir. Ayrıca q2 sonuçlarına göre, örgütsel bağllilı alt faktörlerinden duygusal bağlllı̆̆ın ilgi düzeyi $0,03 \quad(>0.02)$; düşük, devam bağlılığının 0,03 (>0.02); düşük ve normatif bağlılığın 0,06 (>0.02); düşük çıkmıştır. Örgütsel bağlılık alt faktörlerinin işten ayrılma niyeti üzerindeki etki büyüklüğü (f2) duygusal bağlllığın 0,007, devam bağlılığının 0,001 ve normatif bağlılığın ise 0,031 (>0.02); düşük çıkmıştır. Yapısal modelde yer alan değişkenlerin son olarak yapısal eşitlik modelinde analizi yapılmıştır. Elde edilen değerler Tablo 4 'te detaylı olarak verilmektedir.

Tablo 4: Yapısal Eşitlik Modeli Sonuçları

\begin{tabular}{|c|c|c|c|c|c|c|c|c|c|c|}
\hline Hipotezler & $\beta$ & $\overline{\mathbf{x}}$ & S.S. & $t$-değeri & p-değeri & $q^{2}$ & $f^{2}$ & $q^{2}$ & $Q^{2}$ & $\overline{R^{2}}$ \\
\hline Model & & & & & & & & & 0.19 & 0.27 \\
\hline $\begin{array}{ll}\mathrm{H}_{1} & \text { DUY } \gg>N Y T\end{array}$ & $-0,231$ & $-0,225$ & 0,190 & 1,210 & 0,226 & 0.20 & 0.007 & 0,03 & & \\
\hline $\mathrm{H}_{2} \quad \mathrm{DVM} \gg{ }^{\gg N T}$ & 0,101 & 0,104 & 0,247 & 0,408 & 0,683 & 0.07 & 0.001 & 0,03 & & \\
\hline $\mathrm{H}_{3} \quad \mathrm{NRM} \gg{ }^{\gg} \mathrm{NYT}$ & $-0,404$ & $-0,413$ & 0,162 & 2,494 & $0,013^{*}$ & 0.21 & 0.031 & 0,06 & & \\
\hline
\end{tabular}

$p=<0.05^{*}$

Yapısal eşitlik modeli sonuçları incelendiğinde normatif bağlllı̆̆ın $\left(B_{N R M}>N Y T=-0.404, t=2.494, p<0.001\right)$, işten ayrılma niyetine negatif yönlü anlamlı etkisi olduğu tespit edilmiştir. Bu bağlamda $\mathrm{H}_{3}$ hipotezi kabul edilmiştir. Diğer yandan duygusal bağl1lik $\left(\beta_{\mathrm{DUY}>\mathrm{NYT}}=-0.231, \mathrm{t}=1.210, \mathrm{p}<0.001\right)$ ve devam bağll1ığının $\left(\beta_{\mathrm{DVM}>>N Y}=0.101, \mathrm{t}=0.408, \mathrm{p}<0.001\right)$ işten ayrılma niyetine negatif yönlü anlamlı bir etkisinin olmadığı gözlemlenmiştir. Bu doğrultuda $\mathrm{H}_{1}$ ve $\mathrm{H}_{2}$ hipotezleri kabul edilmemiştir. Ayrıca araştırma modeli kapsamında elde edilen sonuçlar Şekil 1'de detaylı olarak verilmektedir.

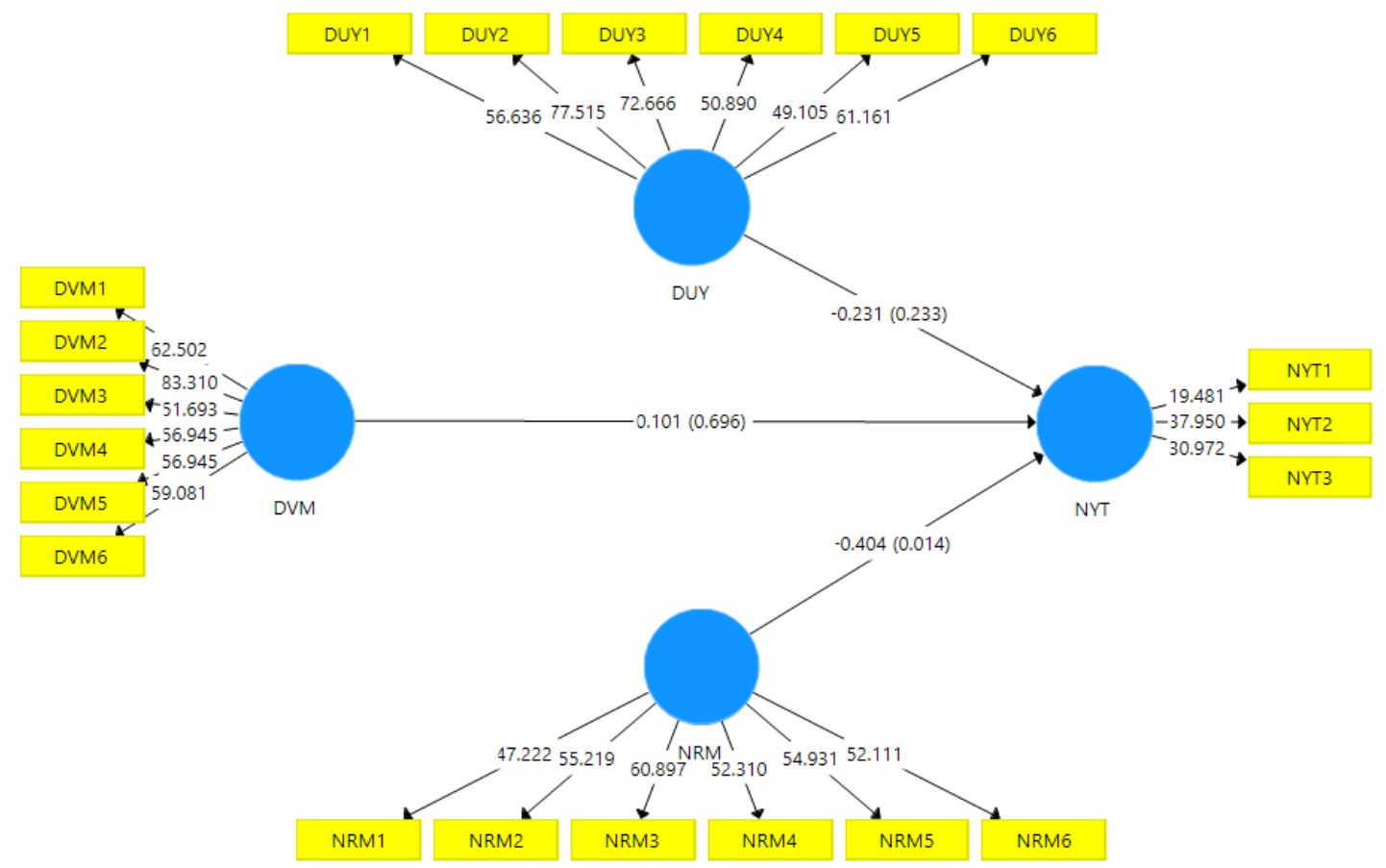

Şekil 1: Yapısal Eşitlik Modeli Sonuçları

Araştırmada ayrıca örgütsel bağlllık alt faktörlerine ayrılmadan işten ayrılma niyetine etkisi incelenmiştir. Örgütsel bağllı̆̆ın işten ayrılma niyeti üzerindeki etkisi (R2) 0,23 olarak hesaplanmıştır. Tahmini ilgi düzeyi (Q2) 0,19 ve etki büyüklüğü ise (f2) 0,31 olarak hesaplanmıştır. Yapısal eşitlik modeli sonucunda örgütsel bağlılığın işten ayrılma niyetini negatif yönde anlamlı olarak etkilediği $\left(\Re_{\mathrm{OB}>>\mathrm{NYT}}=-0.489, \mathrm{t}=15.046, \mathrm{p}<0.001\right)$ tespit edilmiştir.

\section{Sonuç ve öneri}

$\mathrm{Bu}$ araştırmada havayolu sektörü çalışanlarının örgütsel bağlllıklarının işten ayrılma niyetine etkisi incelenmiştir. Araştırmanın özellikle COVID-19 sürecinde yapılmış olması araştırma özgünlüğünü ortaya koymaktadır. Araştırma kapsamında yapılan analiz sonuçlarına göre örgütsel bağlılık alt 
faktörlerinden normatif bağlılı̆̆ın işten ayrılma niyetine pozitif yönde anlamlı etkisi olduğu bulgulanmıştır. Ancak devam ve duygusal bağlllık alt faktörlerinin işten ayrılma niyetine pozitif yönde anlamlı bir etkisi olmadığı tespit edilmiştir.

Havayolu sektörü çalışanlarının bulundukları konumlarda bilişsel yönden bağlılık seviyeleri işlerinden ayrılmalarına engeldir. Çalışanların işlerinden memnun oldukları ve bu durumu mantıksal açıdan düşündüklerinde iyi buldukları görülmektedir. Zincirkıran vd. (2015) enerji sektörü üzerine yaptıkları çalışmada örgütsel bağlılığın işten ayrılma niyetine etkisi olup olmadığını incelemişlerdir. Ancak bu araştırmadan farklı olarak negatif yönde anlamlı bir etki bulunamamıştır. İki araştırmada farklı sonuçlar çıkmış olmasının nedeni yazarların örgütsel bağlılığı genel olarak incelemiş olması olabilir. Ayrıca yine sektör farkı da bu durumun bir diğer nedeni olarak gösterilebilir. Son olarak bu araştırma pandemi sürecinde gerçekleşmiştir. Tüm dünyada kapanma olduğu için alternatif iş olanaklarının bulunmaması çalışanların örgütsel bağlılıklarını normatif yönden anlamlı kılmaktadır. Varol (2017) yaptığı çalışmada bu araştırma sonuçlarından farklı olarak normatif bağlılığın işten ayrılma niyetine negatif yönde etkisi olmadığı, ancak duygusal ve devam bağlılığının pozitif yönde anlamlı etkisi olduğu sonucuna ulaşmışlardır. Havayolu sektörü daha fazla sosyal süreç gerektiren bir sektördür. Ayrıca pandemi süreci insanların yoğun olduğu ortamların tehlike arz etmesi havayolu çalışanlarını duygusal yönden ve devam bakımından etkilese de işten ayrılmaları bir gerekçe olamamaktadır. Diğer yandan ilgili araştırmada örneklem olarak ilaç sektörü ele alınmıştır. Sosyal etkileşimin yoğun olduğu havayolu sektörü çalışanların işlerine normatif yönden daha çok bağlı olduğu söylenebilir. Erdoğdu ve Sökmen (2019) çalışmalarında örgütsel bağlılı̆̆ın işten ayrılma niyetine negatif yönlü anlamlı etkisi olduğu tespit edilmiştir. Bu araştırma ile benzer sonuçlara sahip olan ilgili araştırmada örneklem olarak Kültür ve Turizm Müdürlüğü' ne bağlı birimlerde çalışan bireyler kullanılmıştır. Her iki araştırma da turizm sektörüne bağlı çalışanlar üzerine araştırma yapmıştır. Benzer sonuçların elde edilmesinde turizm sektörüne yönelik yapılan çalışmalar olması söylenebilir.

Havayolu çalışanları hizmet sektörünün yoğun olduğu bir ortamda çalışmaktadır. Ayrıca sirkülasyonun yüksek olması çalışma temposunu da yüksek tutmaktadır. Ancak havayolu sektöründe iş planlamalarının sistemli ve koordineli olması iş ortamını daha olumlu kılabilmektedir. Dolayısıyla işten ayrılma niyeti havayolu çalışanlarında daha düşük olabilmektedir. Araştırma sonuçlarına göre çalışanların işten ayrılma niyetine verdikleri yantların düşük olduğu gözlemlenmiştir. Buradan hareketle havayolu işletmelerini örgütsel bağlllık düzeyini yüksek tutacak bir yönetsel planlama izlemeleri gerekmektedir. Ayrıca çalışanlar ve yöneticiler arasındaki koordinasyonun doğru ve etkili olması yine örgütsel bağlılık düzeyinin yüksek çıkmasında önemlidir. Bu araştırma sonuçları mevcut sistemde çalışanların örgütsel bağlılık düzeylerinin yüksek olduğunu göstermektedir. Ancak işletmelerin çalışanlar ile ilişki düzeyini yüksek tutması işten ayrılma fikrinden daha da ötede işletmeyi çalışanların sahiplenmesi için oldukça mühimdir. Diğer yandan örgütsel bağll1ık alt faktörleri üzerinden elde edilen sonuçlar değerlendirildiğinde, işletmelerin devam bağlılı̆̆ı ve duygusal bağlılık noktasında yetersiz kaldığı görülmektedir. Çalışanların işlerine karşı aitlik hissinin iyi bir seviyeye getirilmesi gerekmektedir. Çalışanların ayın personeli, aile hissi doğuracak uygulamalar gibi süreçlerden geçirilmesi duygusal bağlılıklarını artırabilir. Bu bağlamda işletmelerin yönetsel değerlendirmeler yapması beklenmektedir. Tüm bunlara rağmen araştırmanın gerçekleştirildiği dönemin salgın dönemi olduğu göz önüne alınınca, çalışanlarda maddi kaygılar normatif oluşumlar sağlarken, duygusal yönden ücretsiz izin gibi konular sorunlar oluşturmuş olabilir. Dolayısıyla havayolu işletmelerinin krize müdahale noktasında etkin ve çalışanları koruyucu eylem planları yapmaları elzemdir.

$\mathrm{Bu}$ araştırmada örneklem olarak havayolu çalışanları kullanılmıştıı. Bundan sonraki çalışmalarda turizm sektörüne bağlı diğer alt sektörler araştırılabilir. Ayrıca COVID-19 pandemi süreci ile pandemi sonrası veya öncesi sonuçlar bundan sonra yapılacak araştırmalarda değerlendirilebilir. Araştırmanın bir diğer kıstı ise araştırma modelinde çalışanların sadece örgütsel bağlılıkları incelenmiştir. Bundan sonraki araştırmalarda, tükenme, örgütsel adalet, mobbing gibi iş sürecinde var olabilecek olumsuz durumların işten ayrılma niyetine etkisi incelenebilir. Araştırmada elde edilen sonuçlar özet olarak pandemi sürecinde havayolu çalışanlarının örgütsel bağlllıklarında özellikle normatif yönden iyi olduğu göstermektedir. Bu sonuç pandemi sürecinin etkisinin giderek sektörde azalmaya başladığını da gösterdiği söylenebilir.

\section{Hakem Değerlendirmesi / Peer-review:}

Dış bağımsız

Externally peer-reviewed 


\section{Çıkar Çatışması / Conflict of interests:}

Yazar(lar) çıkar çatışması bildirmemiştir.

The author(s) has (have) no conflict of interest to declare.

\section{Finansal Destek / Grant Support:}

Yazar bu çalışma için finansal destek almadığını beyan etmiştir.

The author declared that this study has received no financial support.

\section{Etik Kurul Onayı / Ethics Committee Approval:}

Bu çalışma için etik kurul onayı, İstanbul Rumeli Üniversitesi Etik Kurulundan 03/08/2021 tarihli 2021/06 sayılı karar ile alınmıştır.

Ethics committee approval was received for this study from Istanbul Rumeli University Ethics Committee on 03/08/2021 and 2021/06. document number.

\section{Kaynakça / References}

Ali, N., \& Baloch, Q. B. (2009). Predictors of organizational commitment and turnover intention of medical representatives (An empirical evidence of Pakistani companies). Journal of managerial sciences, 3(2), 263-273.

Allen, N. J., \& Meyer, J. P. (1990). The Measurement and Antecedents of Affective, Continuance and Normative Commitment to the Organization. Journal of Occupational Psychology, 63(1), 1-18.

Bagozzi, R. P., \& Yi, Y. (1988). On the evaluation of structural equation models. Journal of the academy of marketing science, 16(1), 74-94.

Bakan, İ. (2018). Örgütsel Stratejilerin Temeli Örgütsel Bağlllk, Kavram, Kuram, Sebep ve Sonuçlar. Ankara: Gazi Kitabevi.

Balay R. (2000). Yönetici ve Öğretmenlerde Örgütsel Bağlllık, Ankara. Nobel Yayın Dağıtım.

Bayram, L. (2005). Yönetimde Yeni Bir Paradigma: Örgütsel Bağlılık. Sayıştay Dergisi, 59, 125-137.

Becker, H. S. (1960). Notes on The Concept of Commitment. American Journal of Sociology, 66, 32-42.

Bertelli, A.M. (2006). Determinants of bureaucratic turnover intention: Evidence from the department of the treasury. Journal of Public Administration Research and Theory, 17(2), 235-258.

Blau, G.J. \& Boal, K.B. (1987). İşe dahil olmanın ve örgütsel bağlılığın devir ve devamsızlığı nasıl etkilediğini kavramsallaştırmak. Academy of management review, 12(2), 288-300.

Burgess, R., \& Turner, S. (2000). Seven Key Features for Creating and Sustaining Commitment. International Journal of Project Management, 18, 225-233.

Bükey, A. \& Aktaş, M. (2019). Tüketicilerin etnosentrik eğilimlerinin müşteri sadakati üzerine etkisi. Social, Mentality and Researcher Thinkers Journal, 5(26), 1929-1935.

Byrne, B. M. (1994). Structural equation modeling with EQS and EQS/Windows: Basic concepts, applications, and programming. Sage Pub.

Cotton, J.L. \& Tuttle, J.F. (1986). Employee turnover: a meta-analysis and review with implications for research. Academy of Management Review, 11(1), 55-70.

Çırpan, H. (1999). Örgütsel Öğrenme İklimi ve Örgüte Bă̆lllık İlişkisi: Bir Alan Araştırması. Doktora Tezi. İstanbul, İstanbul Üniversitesi

Demirel, Y. (2018). Örgütsel güvenin örgütsel bağlllık üzerine etkisi: Tekstil sektörü çalışanlarına yönelik bir araştırma. Yönetim ve Ekonomi. Celal Bayar Üniversitesi İktisadi ve İdari Bilimler Fakültesi Dergisi, 15(2), 179-194. 
Demirtaş, E. \& Şama, E. (2016). Okullarda Dönüşümcü Liderlik ve Örgütsel Bağlllık İlişkisi. Iğdır Üniversitesi Sosyal Bilimler Dergisi, (10), 275-298.

Dick, G., \& Metcalfe, B. (2001). Managerial Factors and Organizational Commitment: A Comparative Study of Police Officers and Civilian Staff. The International Journal of Public Sector Management, 14(2), 111-128.

Erdoğdu, F. B., \& Sökmen, A. (2019). Örgütsel bağlllık ile iş tatmini ve işten ayrılma niyeti ilişkisinde örgütsel vatandaşlık davranışının aracılık rolü. Journal of Tourism and Gastronomy Studies, 7(1), 244264.

Fornell, C., \& Larcker, D. F. (1981). Evaluating structural equation models with unobservable variables and measurement error. Journal of marketing research, 18(1), 39-50.

Göral, M., Kement, Ü. \& Bükey, A. (2021). Turizm Akademisyenlerinin "Kongre" Kavramı ile İlgili Kullandıkları Metaforlar Aracılığıyla Kongrelere İlişkin Algılarının Değerlendirilmesi, Turizm ve İşletme Bilimleri Dergisi, 1(1), 70-83.

Hair, J. F., Risher, J. J., Sarstedt, M., \& Ringle, C. M. (2019). When to use and how to report the results of PLS-SEM. European business review, 27(3), 197-211.

Halis, M., Çamlıbel, Z. \& Bükey, A. (2020). The Effect of personality characteristics on volunteer motivation: A study on ngo employees in the covid19 pandemic process. Revista Argentina de Clinica Psicologica, 5(29), 922-934.

Hitka, M., Štarchoň., Caha, Z., Lorincová, S. \& Sedliačiková, M. (2021). The global health pandemic and its impact on the motivation of employees in micro and small enterprises: a case study in the Slovak Republic, Economic Research-Ekonomska Istraživanja, 1(21), 1-22.

Hu, L. T., \& Bentler, P. M. (1999). Cutoff criteria for fit indexes in covariance structure analysis: Conventional criteria versus new alternatives. Structural equation modeling: a multidisciplinary journal, $6(1), 1-55$.

İmamoğlu, G. (2011). İlköğretim okulu öğretmenlerinin örgütsel bağlllı düzeyleri ve örgütsel adalet algılar arasındaki ilişki. Yüksek Lisans Tezi. Gazi Üniversitesi Eğitim Bilimleri Enstitüsü, Ankara.

Joo, B.K.B. \& Park, S. (2010). Career satisfaction, organizational commitment, and turnover intention: The effects of goal orientation, organizational learning culture and developmental feedback. Leadership \& Organization Development Journal, 31(6), 482-500.

Kaiser, H. F. (1974). An index of factorial simplicity. Psychometrika, 39(1), 31-36.

Kanter, R. M., (1968). Commitment and Social Organization: A Study of Commitment Mechanisms in Utopian Communitise. American Sociological Review, 33(4), 499-517.

Kanwar, Y.P.S., Singh, A.K., \& Kodwani, A.D. (2012). A study of job satisfaction, organizational commitment and turnover intent among the IT and ITES sector employees. Vision: The Journal of Business Perspective, 16(1), 27-35.

Kement, Ü., \& Batga, B. (2016). Mobbing'in Örgütsel Bağlllı̆̆a Etkisi: Eğlence ve İkram lı Hizmet Veren Rekreasyon İşletmelerinde Bir Araştırma. İşletme Araştırmaları Dergisi, 8(4), 400-420.

Kement, U., Çavuşoğlu, S., Demiră̆, B., Durmaz, Y., \& Bükey, A. (2020). Effect of perception of COVID19 and nonpharmaceutical intervention on desire and behavioral intention in touristic travels in Turkey. Journal of Hospitality and Tourism Insights, ahead-of- rint(ahead-of-print). https://doi.org/10.1108/jhti-07-2020-0139.

Khanna, D. (2021). Dauntingly Dashing Debutante on Dart during the Depressing COVID-19 Pandemic in Hospitality Sector. İçinde, Rana, V. S., Bathla, G., \& Raina, A. (Eds.), Eureka Publications, Pune, Maharashtra, 411027, 317-331.

Khatri, N., Fern, C. T., \& Budhwar, P. (2001). Explaining employee turnover in an Asian context. Human Resource Management Journal, 11(1), 54-74.

Krejcie, R. V., \& Morgan, D. W. (1970). Determining sample size for research activities. Educational and psychological measurement, 30(3), 607-610.

Lance, C. E. (1988). Job performance as a moderator of the satisfaction-turnover intention relation: An empirical contrast of two perspectives. Journal of Organizational Behavior, 9(3), 271-280. 
Meşe, G. (2007). Endüstri ve Örgüt Psikolojisinde Örgütsel Bağhllı̆̆ın Anlamı, Endüstriyel Klinik Psikoloji ve İnsan Kaynaklarn Yönetimi, İstanbul: Beta Yayınevi, 239-256.

Meyer, J. P., \& Allen, N. J. (1991). A three-component conceptualization of organizational commitment. Human resource management review, 1(1), 61-89.

Mobley, W. H. (1977), Intermediate Linkages in the Relationship Between Job Satisfaction and Employee Turnover. Journal of Applied Psychology, 62(2), 237- 240.

Muchinsky, P.M. \& Morrow, P.C. (1980). A multidisciplinary model of voluntary turnover. Journal of Occupational Vocational Behavior, 17(3), 263-290.

Newton, L. A. \& Shore, L. M. (1992). A Model of Union Membership: Instrumentality, Commitment and Opposition. Academy of Management Review, 17(2), 275-298.

O'Reilly, C. \& Chatman, J. (1986). Organizational Commitment and Psychological Attachment: The Effects of Compliance, Identification, and Internationalization on Prosocial Behavior. Journal of Applied Psychology. 71(3), 492-499.

Özcan, E., Vardarlıer, P., Karabay, M., Konakay, G. \& Çetin, C. (2012). Liderliğin Örgütsel Vatandaşlık Davranışı ve İşten Ayrılma Niyeti Üzerindeki Etkisinde Güvenin Rolü, Öneri Dergisi, 10(37), 1-13.

Penley, L. E. \& Gould, S. (1988). Etzioni's Model Of Organizational Involvement: A Perspective For Understanding Commitment To Organizations. Journal of Organizational Behavior, 9, 43-59.

Pitts, D., Marvel, J. \& Fernandez, S. (2011). So hard to say goodbye? Turnover intention among U.S. Federal Employees. Public Administration Review, September/October, 751-760.

Salancik, G. R. (1977). Commitment is too easy. Organizatonal Dynamics, 62-80.

Salleh, R., Nair, M. S., \& Harun, H. (2012). Job satisfaction, organizational commitment, and turnover intention: A case study on employees of a retail company in Malaysia. International Journal of Economics and Management Engineering, 6(12), 3429-3436.

Tarigan, V. \& Ariani, D.W. (2015). Ampirik çalışma ilişkileri iş tatmini, örgütsel bağlılık ve işten ayrılma niyeti. Yönetim ve Uygulamalı Ekonomideki Gelişmeler, 5(2), 21.

Ural, A. \& Kılıç, İ. (2018). Bilimsel Araştırma Süreci ve SPSS ile Veri Analizi, Ankara: Detay Yayıncılık.

Uslu, A. (2012). Örgütsel bağhllık, daimi ve geçici işçilerin örgütsel bağhllık algılarn üzerinde bir araştırma ve Muş şeker fabrikasında bir alan çalışması. Yayınlanmamış yüksek lisans tezi, Kahramanmaraş Sütçü İmam Üniversitesi, Sosyal Bilimler Enstitüsü, Kahramanmaraş.

Uygur, A. (2009). Örgütsel Bağlllık ve İşe Bağlllık. Barış Platin Kitapevi, Ankara.

Ünler, E. (2006). Örgütte Bağlllı̆̆ın İşin Nitelikleri ve Davranış Düzeltme Uygulamasıyla İlişkisi, Yönetim Bilimleri Dergisi, 4(1), 95-115.

Varol, F. (2017). Çalışanların Örgütsel Bağlllık ve İş Tatminlerinin İşten Ayrılma Niyetlerine Olan Etkisi: İlaç Sektörü Örneği. Selçuk Üniversitesi Sosyal Bilimler Enstitüsü Dergisi, (38), 200-208.

Voorhees, C. M., Brady, M. K., Calantone, R., \& Ramirez, E. (2016). Discriminant validity testing in marketing: an analysis, causes for concern, and proposed remedies. Journal of the academy of marketing science, 44(1), 119-134.

Whyte, W. (1956). The organization man. Simon and Schuster, United States.

Zincirkıran, M., Çelik, G. M., Ceylan, A. K., \& Emhan, A. (2015). İşgörenlerin örgütsel bağlllık, işten ayrılma niyeti, iş stresi ve iş tatmininin örgütsel performans üzerindeki etkisi: Enerji sektöründe bir araştırma. Finans Politik ve Ekonomik Yorumlar, (600), 59-71. 